\title{
LOS CÓDIGOS DE ÉTICAY LOS CÓDIGOS DE CONDUCTA EN LA PROMOCIÓN DE LA ÉTICA ORGANIZACIONAL
}

\author{
JENNIFER ISABEL ARROYO CHACÓN \\ Contraloría General de la República, Costa Rica \\ prof.jenniferarroyo@yahoo.com
}

\section{RESUMEN}

El presente texto analiza el papel de los códigos de ética y códigos de conducta como promotores de la ética organizacional, dada su importancia para las empresas públicas y privadas, y su vinculación con el clima y la cultura organizacional. Figuras que se basan en los valores corporativos que rigen la entidad y que permitan consolidar una buena imagen, interna y externa, de respeto a la ética y reproche a conductas ilícitas e inadecuadas. Se explican los conceptos de código de ética y código de conducta, sus contenidos más frecuentes y el proceso de elaboración. Se diferencian ambas figuras entre sí, y con otros institutos afines como acuerdos marcoglobales, reglamento interno de trabajo y código de buen gobierno corporativo. Finalmente, se destaca su papel en la promoción de la ética organizacional, aspecto que cada vez reviste de mayor importancia para las empresas públicas y privadas por las implicaciones negativas que posee en su imagen las actuaciones contrarias a la conducta ética que la sociedad demanda de ellas.

Palabras clave: códigos de ética, códigos de conducta, ética, lucha contra la corrupción

\begin{abstract}
This paper analyzes the role of codes of ethics and codes of conduct as promoters of organizational ethics, in virtue of their importance and necessity in public and private enterprises and their linkage with organizational climate and culture, which must be based on the corporate values that govern the entity and that allow to consolidate a good internal and external image, of respect for ethics and reproach to illegal and inadequate conduct. The concepts of code of ethics and code of conduct, its most frequent contents and the elaboration process are explained. Then, the differences between both types of codes are established, and with other related institutes such as global framework agreements, internal work regulations and code of good corporate governance. Finally, it highlights its role in promoting organizational ethics, aspect that is increasingly reviewed as being of mayor importance for public and private companies because of the negative implications that have in their image the actions contrary to the ethical conduct that society demands them.
\end{abstract}

Keywords: codes of ethics, codes of conduct, ethics, anti-corruption. 


\section{INTRODUCCIÓN}

La sociedad actual pasa por una crisis de valores, situación que se refleja en las denuncias de actos de corrupción que se hacen públicas diariamente, por diversos medios, pero principalmente en redes sociales. Denuncias en contra de las empresas públicas y empresas privadas; o bien, en colusión del sector público y privado. Dichos actos provocan el rechazo de la ciudadanía y consumidores, lo que causa pérdida de credibilidad en las instituciones estatales y daño a la imagen y, por ende, pérdidas económicas para las empresas privadas. De allí que la preocupación por la ética sea una tarea a la cual deben ocuparse las empresas, desde el ámbito legal y de la gestión del recurso humano.

En consecuencia, se procede a analizar la ética organizacional, entendida como la ética aplicada a la relación ética-empresa, que constituye la base de los valores corporativos que forman el clima organizacional y finalmente, la cultura organizacional. Lo anterior dada la necesidad de construir una cultura organizacional basada en un fuerte sistema de valores éticos que consoliden una imagen íntegra de la empresa pública o privada.

Con el objetivo de gestionar de forma adecuada la ética organizacional se recurre a diversos mecanismos, entre ellos los códigos de ética y códigos de conducta. Instrumentos que guían el actuar de la clase trabajadora de una institución para que actúe apegada a los valores corporativos y así evitar lesionar la imagen empresarial frente a la clientela y la ciudadanía. Precisamente, en los siguientes acápites se analizará con detalle el concepto y contenido de estos instrumentos y los elementos diferenciadores con otros instrumentos similares.

\section{Ética en la empresa}

\section{ÉTICA}

El término ética proviene de la palabra "ethos", siendo objeto de especial estudio por filósofos y pensadores griegos y que, actualmente, resulta de gran relevancia. Incluso puede hablarse de un resurgimiento del estudio de la ética.

González (2004) recalca la vinculación que posee la ética con la moral, la cual se refiere al conjunto de valores, principios, normas de conducta, prohibiciones, etc. de un colectivo, que forma un sistema coherente dentro de una determinada época histórica y que sirve como modelo ideal de buena conducta, socialmente aceptada y establecida. No obstante, ambos conceptos abarcan ámbitos distintos, dado que la ética es una reflexión sobre el hecho moral que busca las razones que justifican que utilicemos un sistema moral u otro, siendo por lo tanto una parte de la filosofía que analiza un fenómeno moral en general.

Ética se puede definir como la disciplina normativa, basada en la razón, que se encarga de discriminar cuáles actos se califican como correctos y cuáles son incorrectos. Su propósito es el examen y la explicación de los actos humanos: la conducta, las actitudes y otras manifestaciones del ser humano ante los acontecimientos diarios.

Por lo tanto, la ética es el conjunto de normas morales que regulan el comportamiento de los individuos en un determinado grupo social, que se compone de la ética individual. La ética social es, precisamente, la sumatoria de las éticas individuales, que al final, también son decisiones racionales que deben ser reflexionadas y muy bien analizadas para que vayan siempre en beneficio de la sociedad, que nos da la razón de ser y por la cual se debe responder. La ética posee diversas ramas según su ámbito de apli- 
cación, siendo de interés para el presente texto la ética en la empresa.

\section{ÉTICA EN LA EMPRESA}

Desde el surgimiento de la empresa en la sociedad como aquella unidad que combina los diversos factores de la producción para la realización de actividades industriales, mercantiles o de prestación de servicios, se ha discutido el papel que esta debe cumplir y la ética aplicable a su labor. En sus inicios, se consideró que el único objetivo que debía alcanzar era la generación de riqueza. No obstante, la clientela, la ciudadanía y la sociedad en general, comenzaron a exigir que alcanzar dicho objetivo en respeto a los valores éticos imperantes, en apego a actuaciones honestas y responsables en el momento de hacer negocios, de tal manera que se comenzó a castigar la imagen y el nivel de consumo de productos y servicios ofrecidos por aquellas empresas que no satisfacían dichas expectativas.

Este último aspecto es particularmente relevante al considerar que la imagen y la reputación corporativa son activos intangibles que, incluso, pueden llegar a ser una ventaja competitiva en el mercado. Por tanto, las denuncias de conductas antiéticas por parte de una empresa pública o privada, poseen un impacto relevante en sus intereses empresariales.

Derivado de lo anterior, ha surgido una preocupación por promover un actuar ético de parte de los integrantes de la organización, lo cual ha provocado que las autoridades administrativas se avoquen a incentivar conductas éticas en sus trabajadores, tomándolas como pilar para la toma de decisiones. Esto además de evitar actuaciones contrarias a los valores corporativos que les rigen, procurando consolidar la imagen empresarial frente a la clientela y sociedad en general.
Al respecto, Elegido (1998) se pronuncia sobre las ventajas intangibles que posee para las empresas un actuar ético y crearse una buena reputación a lo largo del tiempo, basada en las acciones pasadas, lo cual contribuye al desarrollo del negocio:

La pregunta que viene a cuento es si un comportamiento consistentemente ético por sí mismo contribuye positivamente al éxito en los negocios. Parece claro que sí, al fomentar tres ingredientes clave para ese éxito. El comportamiento ético contribuye a la buena reputación de una firma y a que otros grupos se muestren dispuestos a confiar en ella, y ello promueve la dedicación de los empleados al éxito de la firma. Además de contribuir al éxito en los negocios, estos factores también poseen la característica, altamente deseable, de no ser fácilmente imitables y por ello pueden aportar una ventaja competitiva sostenible (Elegido, 1998, p. 26).

Por tanto, la ética de la empresa se refiere a las normas y principios que se utilizan para resolver los diversos problemas morales y de conducta dentro del contexto empresarial, que procura aplicar principios éticos en la toma de decisiones y en acciones concretas, y aporta herramientas que elevan el nivel ético de las empresas.

\section{ÉTICA ORGANIZACIONAL}

Derivado de la ética empresarial, surge la ética organizacional. Puede definirse como la rama de la ética aplicada a las organizaciones que corresponde al conjunto de valores, normas y principios que reflejan la cultura organizacional. La ética organizacional se compone de la ética individual de cada uno de sus miembros, que en su conjunto forman la ética de la organización. Posee una relación bidimensional: la ética individual influye en la ética organizacional pero, a su vez, el ambiente ético de una organización incide en el actuar ético individual de la persona vinculada con ella. 
Para Lozano (2005), la ética organizacional debe ser entendida como un horizonte de valores compartidos que permite transformar y orientar las prácticas organizacionales, creando al mismo tiempo razones éticas y con significado. Se refiere a un proceso organizacional que integra las dimensiones éticas que hace posible la creación de dicho horizonte ético y la convivencia en su seno. El citado autor recalca que se trata de un proceso, lo cual implica que no es algo que viene dado desde el exterior, sino que más bien debe crearse desde el interior de la organización con la participación de todos los miembros. Textualmente define este concepto como:

El término ética organizacional se refiere al conjunto de valores que identifica una organización, según la perciben tanto las personas que trabajan en ella como las personas que tienen algún tipo de relación con ella. Este conjunto de valores se puede considerar en un sentido amplio - es decir, el conjunto de valores que estructuran la organización y sus prácticas - o en un sentido más estricto - en este caso nos referiríamos sólo a esos valores que expresan la visión, la razón de ser y los compromisos de la organización, y están ligados a su identidad (Lozano, 2005, p. 19).

Para Cleghorn (2005), la ética organizacional debe partir de los valores personales del equipo de trabajo, porque estos constituirán la base de los valores de la organización. Posteriormente debe tomarse en cuenta la filosofía operativa de la entidad, la cultura organizacional, los grupos de interés que fluctúan en la organización, para finalmente construir la ética organizacional.

La construcción de la ética organizacional es una de las tareas de las cuales debe ocuparse la administración en su conjunto, con el fin de evitar las consecuencias negativas que provoca una ética organizacional débil como: procesos judiciales en su contra, sanciones sobre sus produc- tos, daños ambientales, reclamaciones laborales por acoso sexual y mobbing, inclusión en listas negras, desconfianza de proveedores, autoridades, trabajadores y clientes, daño a la imagen y demás vinculadas. Al contrario, la promoción de la ética organizacional permite incrementar la motivación para el trabajo y, por lo tanto, la satisfacción de la clase trabajadora, en virtud del respeto a los valores éticos que motivan a las personas y afectan su rendimiento y actitud, a la vez atraen a personal de mayor cualificación.

Esta fortalece la cultura organizacional y mejora la imagen institucional, activo intangible, que es utilizada como una ventaja competitiva en el sector privado y un medio para ganar credibilidad ciudadana en el sector público. Se construye a partir de las actuaciones y actitudes de las personas que forman la organización, sustentadas en unos valores y criterios compartidos.

\section{Cultura y clima organizacional}

\section{CULTURA ORGANIZACIONAL}

La ética organizacional se basa en la cultura organizacional, la cual se entiende como el conjunto de creencias, hábitos, valores, actitudes, tradiciones entre los grupos existentes en todas las organizaciones. Para Belalcázar (2012), la cultura organizacional puede ser considerada como un sistema de significaciones, expresiones, categorías, imágenes, modos de vida, creencias, valores, reglas, normas, procedimientos que son aceptados, pública y colectivamente, en el seno de un grupo social, transmitidos a través de las generaciones.

Toda organización está inmersa en una sociedad que posee su propia cultura, que se integra por un sistema de leyes, valores, costumbres propias, que sin duda influyen en ella. Cada organización posee una cultura única e intangible que se compone del conjunto de supuestos, convic- 
ciones, valores y normas que comparten todos sus miembros y que guían sus actuaciones.

Por tanto, la cultura organizacional es la personalidad de la empresa que integra sus objetivos, filosofía empresarial, misión, visión, valores y formas de hacer las cosas. Se compone de la cultura individual de cada persona colaboradora, pero que, a su vez, debe interiorizar desde el primer momento en que ingresa a la organización, por ende, le permea en su propia cultura. Al integrar la organización actúa como un agente dentro de la cultura organizacional.

Dada la importancia que posee la cultura organizacional y su impacto en el desarrollo de la actividad que desenvuelven las organizaciones, se requiere un esfuerzo de su parte, para construir una cultura organizacional basada en una ética organizacional sólida. Para ello, se deben formular estrategias y estructuras éticas claras, teniendo en cuenta las oportunidades y los riesgos; los recursos y las competencias; los valores personales y las preferencias; y las responsabilidades sociales y económicas.

\section{CLIMA ORGANIZACIONAL}

Como elemento integrante de la cultura organizacional se encuentra el clima organizacional. Se refiere a las características del medio ambiente de trabajo que son percibidas directa o indirectamente por la población trabajadora que se desempeña en la organización y que posee repercusiones sobre su comportamiento. El clima es una variable que interviene entre los factores del sistema organizacional y el comportamiento individual, por lo que es relativamente permanentes en el tiempo, se diferencia de una organización a otra y de una sección a otra dentro de una misma empresa.

Sandoval-Caraveo (2004) define clima organizacional como el ambiente de trabajo percibido por los miembros de la organización, que in- cluye la estructura, el estilo de liderazgo, la comunicación, la motivación y las recompensas, todo ello ejerce influencia directa en el comportamiento y desempeño de los individuos. Para Domínguez, Ramírez y Campos (2013) el clima organizacional se basa en los patrones de conducta recurrentes de los trabajadores de una organización que resulta más maleable que la cultura organizacional:

El clima organizacional se basa en las percepciones individuales, a menudo se define como los patrones recurrentes de comportamiento, actitudes y sentimientos que caracterizan la vida en la organización, y se refieren a las situaciones actuales en una organización y los vínculos entre los grupos de trabajo, los empleados y el desempeño laboral. Por lo tanto, casi siempre la gerencia manipula el clima con mayor facilidad que la cultura, con el fin de afectar de manera directa el comportamiento de los empleados (p. 62).

Belalcázar (2012) diferencia cultura organizacional de clima organizacional. Aclara que, mientras que el clima hace referencia a las expectativas y demandas que las personas miembros de una organización tienen sobre ella y al grado de satisfacción de las mismas en el funcionamiento de esa organización, la cultura se refiere al sistema de valores que está presente y conforma la organización. De este se desprenden una serie de normas, pautas de conducta, artefactos, etc., con los que los individuos se sienten más o menos identificados.

La construcción de un buen clima organizacional que contribuya a una cultura organizacional, basada en la ética organizacional, requiere de la ejecución de múltiples actividades tales como: una codificación ética, programas de formación ética, un consejo con una representación amplia, auditorías éticas, canales abiertos para el flujo de información. Todo esto para que exista una buena comunicación y una consulta per- 
manente a todos los niveles, y nombramiento de altos directivos corporativos. Precisamente, dentro de la codificación ética se incluye la elaboración de los códigos de ética y códigos de conducta como promotores de la ética organizacional, que son objeto del presente análisis.

\section{VALORES CORPORATIVOS}

Uno de los pilares de la ética organizacional es el conjunto de valores que posee la organización. Estos son entendidos como un grupo de creencias que la empresa tiene sobre determinadas conductas específicas y sobre los fines u objetivos de su existencia.

Los valores son definidos por cada organización y constituyen la base desde la cual sus líderes actúan, a partir de los cuales se establecen planes y estrategias organizacionales, se puede afirmar que dirigen a las organizaciones. Son los principios básicos que deben ser cumplidos si se quiere sobrevivir en esa organización.

De acuerdo con Hultman (2005), los valores son los conceptos psicológicos, internos a una persona. Las organizaciones, por sí mismas, carecen de valores, pero al estar conformadas por personas, sus culturas son expresiones de los valores existentes y son compartidos de distinta manera por los miembros de la organización.

Para Velásquez de Naime, Rodríguez y Guaita (2012), los valores organizacionales, proporcionan un sentido de dirección común para toda la población trabajadora y establecen directrices para su compromiso diario, siendo promotores para alcanzar los resultados. Por tanto, son el soporte de la gerencia, para promover condiciones y pautas para el éxito de la organización. Los valores corporativos más recurrentes son: respeto, ética, recurso humano, satisfacción de los clientes, optimización de los recursos, calidad, rentabilidad, responsabilidad social empresarial, trabajo en equipo, responsabilidad, tecnología de punta, seguridad, mejora continua, innovación y sentido de pertenencia.

Por su parte, Gilli (2011), define los valores como la base de la cultura organizacional y sobre la cual se toman las decisiones empresariales:

Los valores son los cimientos de cualquier cultura organizacional porque proporcionan un sentido de dirección común y pautas para el comportamiento diario. Hablar del sistema de valores para la toma de decisiones supone que la consideración de los mismos es sistemática, es decir, que nuestras decisiones no son arbitrarias, intuitivas o responden a una racionalidad meramente instrumental, sino que se dispone de un sistema de valores que asegurará una decisión ética (p. 60).ca

Los individuos integrantes de una organización poseen su propia escala de valores, construidos en espacios como familia, escuela, sociedad e igualmente, el trabajo, que trasladan a sus obligaciones labores. No obstante, la organización como tal también posee su propia escala de valores que debe trasladarlas a sus miembros.

Junto con su Misión y Visión, debe establecer dentro de su filosofía empresarial, las actitudes que representarán su marco básico de conducta y procurar comunicarlas, de modo que sean reconocidas y seguidas por el personal. Por tanto, los valores representan los referentes fundamentales dentro de los cuales se va a dirigir la conducta de la organización. Debido a que sus miembros pueden tener una escala de valores distinta, la empresa debe desarrollar métodos de inducción y promoción que permitan que lleguen a ser compartidos por todos sus integrantes, para lograr el comportamiento elegido y deseado por la empresa.

La concordancia entre los valores individuales y los valores organizacionales reflejarán el clima dentro de la empresa, donde sus integrantes va- 
Ioran las mismas cosas y aplican esos valores en beneficio de la organización como una unidad, dándose una relación bidireccional. Lo expuesto se presenta en la Figura 1.

\section{FIGURA 1|}

\section{ELEMENTOS DE LA CULTURA ORGANIZACIONAL BASADA EN VALORES}

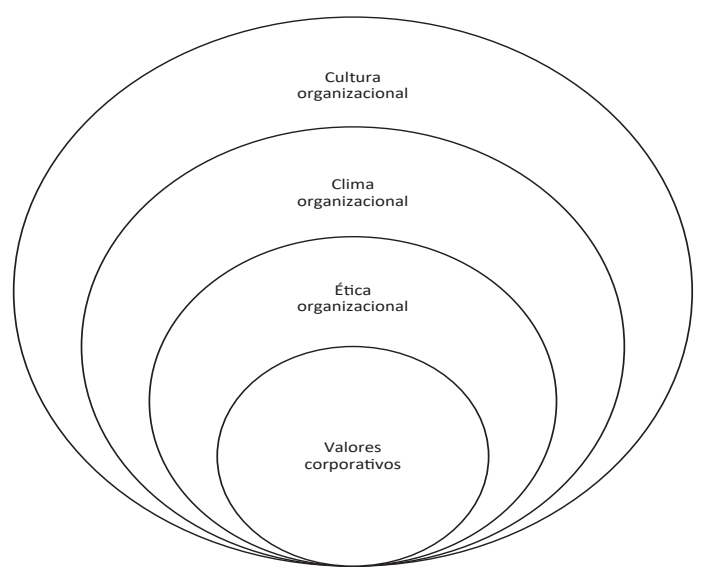

Fuente: Elaboración propia, con base en la bibliografía consultada

\section{El papel códigos de ética y códigos de conducta en la promoción de la ética}

\section{CONCEPTO DE CÓDIGO DE ÉTICA}

El código de ética es un instrumento promotor de la ética organizacional, que integra los valores corporativos. Su propósito es impulsar, consolidar y velar por una cultura de valores y principios éticos que guíen la labor cotidiana de los trabajadores y la toma de decisiones de las autoridades administrativas de la entidad.

Corresponde a un valioso instrumento al que pueden recurrir las empresas para expresar y recopilar el abanico de valores, principios y normas éticas que la organización ha hecho propios. En los códigos suelen formularse por separado aquellos imperativos conductuales considera- dos obligatorios, de los óptimos, deseables o prohibidos. Su aplicación no prevalece sobre las disposiciones legales; más aún, busca una excelencia mayor a la que obliga la ley vigente.

Para Cleghorn (2005), la redacción del código de ética corresponde a una ética de valores mínimos, a los mínimos valores indispensables que la organización ha acordado mediante consenso que serán los que regirán el actuar institucional.

La ética de valores es de mínimos, ya que propone que los miembros de un grupo o organización definan los valores que los guían y lleguen a un consenso sobre los mínimos valores que todos comparten. El código de valores así creado debe estar presente en todos los ambientes de la organización y debe guiar todas las acciones de la empresa. No debe ser un convidado de piedra Al igual que en los otros esfuerzos de cambio, este código no debe ser impuesto. Debe ser adoptado por la mayor cantidad de trabajadores posibles, ya que son ellos los que posteriormente deben respetarlo (Cleghorn, 2005, p. 94).

El Código de ética se construye de forma colaborativa en la organización, pues recoge los valores corporativos, que parten de los valores individuales de sus integrantes, de allí que demanda la participación de todos los miembros de la entidad. La participación de la alta jerarquía resulta fundamental, pues incrementa el compromiso de su parte para cumplirlo, dado que los valores plasmados reflejan sus valores personales.

En el ámbito jurídico se trata de un instrumento de rango menor, dado que carece de potestad coercitiva. Se trata de buenas prácticas laborales que sirven de complemento a las normas laborales legales y reglamentarias existentes. A su vez, funge como herramienta al programa de integridad institucional que, en forma objetiva y no controversial, dentro del marco jurídico, coadyuve a elevar el nivel de integridad y el combate a la corrupción dentro de la entidad. 
Poseer un código de ética trae beneficios para las empresas e instituciones tales como: mejorar la imagen institucional y la reputación de sus colaboradores, desincentivar prácticas corruptas y antiéticas, construir relaciones sólidas con los proveedores, acreedores, prestadores de servicios y otros terceros vinculados, prevenir violaciones legales y reglamentarias debido a que los códigos ayudan a evitar estos actos y en caso de detectarlos, mitigar sus efectos. Los códigos de ética sirven de instrumento para prevenir conflictos, tanto internos como externos, en virtud de que también alcanzan a los terceros relacionados con la institución.

También, logran mejorar la eficiencia, eficacia y economía con la que se administran los recursos institucionales, permiten generar lealtad, cooperación y compañerismo entre los trabajadores lo cual incide positivamente en el clima organizacional. Finalmente, como aspecto de mayor relevancia, son un pilar para construir una cultura organizacional basada en la ética organizacional al incluir a todos los estratos de la empresa, y guiar al personal a actuar regidos por los valores corporativos.

\section{CONTENIDOS MÁS COMUNES DE LOS CÓDIGOS DE ÉTICA}

El código de ética debe incluir los valores corporativos más importantes, aquellos que van a guiar la actuación de toda la organización. Se debe determinar cuáles valores van a regir en los distintos ámbitos de relación de los trabajadores y de la empresa (ver figura 2).

Los valores corporativos pueden variar dependiendo de la esfera de relaciones que se trate. Se redactan, de manera general e incluso aspiracional; es decir, la actitud deseada de sus miembros en cada uno de dichos ámbitos, los cuales serán la base para elaborar el código de conducta que resulta más amplio y concreto que el código de ética.

FIGURA 2

ÁMBITOS DE RELACIÓN Y VALORES ÉTICOS CORPORATIVOS

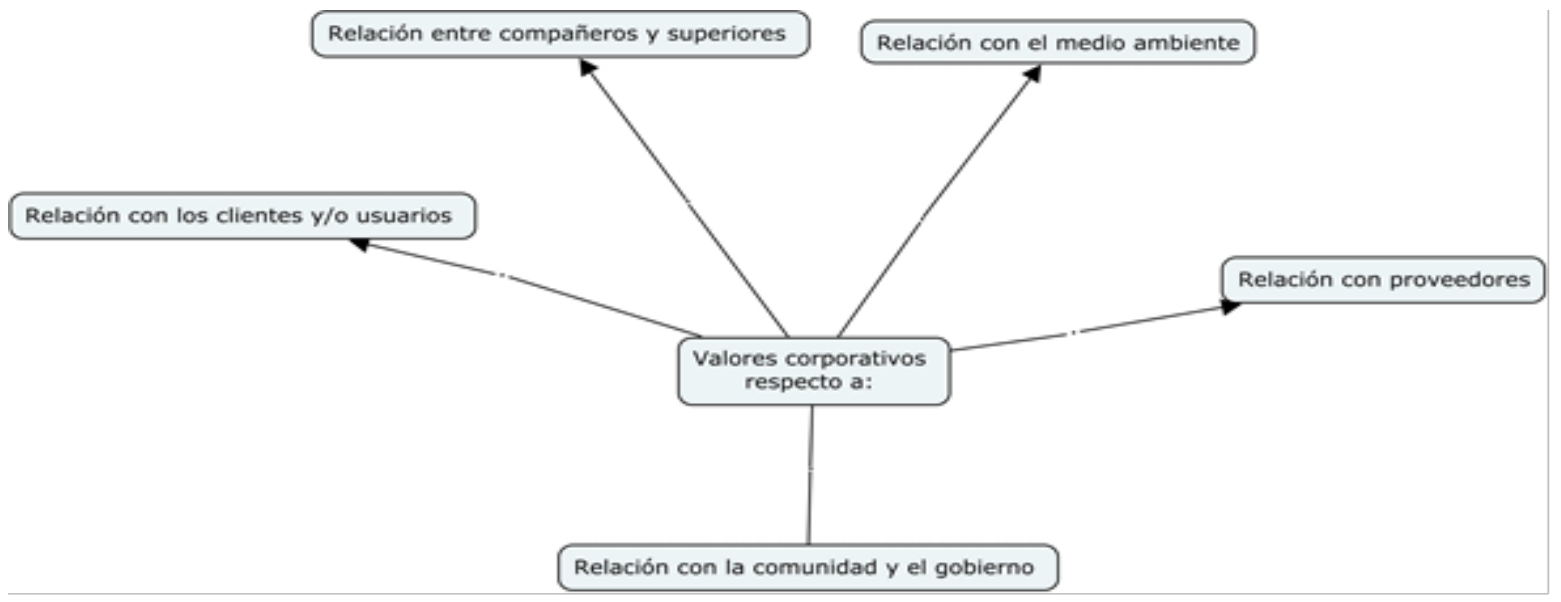

Fuente: Elaboración propia, con base en la bibliografía consultada 


\section{CONCEPTO DE CÓDIGO DE CONDUCTA}

El código de conducta tiene como objetivo establecer las pautas de comportamiento de observancia obligatoria para los trabajadores y para terceros relacionados con la empresa, partiendo de los valores corporativos definidos en el código de ética. La Organización Internacional del Trabajo (en adelante OIT) lo define como declaraciones que las compañías hacen públicas y que contienen los principios, políticas y reglas que se comprometen a cumplir, ejecutar o promover con respecto a determinada materia o ámbito.

Los códigos de conducta incorporan una base ética o de principios que fundamentan los compromisos que la empresa asume a través de ellos. Se recalca que son adoptados de manera voluntaria, por iniciativa propia.

El código de conducta se escribe con un lenguaje claro y preciso, detalla el comportamiento que se espera de la población trabajadora en el ámbito laboral, así como de los terceros relacionados con la institución y, finalmente, enlista las consecuencias que conlleva actuar de forma contraria. Los códigos de conducta describen las normas de comportamiento que contribuyen a que la organización cumpla con sus objetivos de forma eficiente y eficaz.

De tal manera, que se incluyen las conductas específicas que son permitidas y aquellas que son prohibidas, con las sanciones que su vulneración implica, dándole además seguridad jurídica al trabajador, al poder tener reglas claras en su relación laboral. En la tabla 1 se encuentran cuatro tipos diferentes de conductas.

Contar con un código de conducta le permite a la organización prevenir conflictos, tanto internos como externos. Dado que, al igual que el Código de Ética, posee alcance a terceros relacionados con la institución; puede mejorar la eficiencia, eficacia y economía con la que se administran los recursos públicos; generar lealtad, cooperación y compañerismo entre los trabajadores; mejorar el ambiente laboral; establecer una cultura ética interna, motivando la participación de los colaboradores en la elaboración y divulgación del mismo. Además, atrae a personal calificado y con altos valores éticos para formar parte de una institución que fomenta los

\section{TABLA 1}

\section{TIPOS DE CONDUCTAS INCLUIDAS EN EL CÓDIGO DE CONDUCTA}

\section{Conductas obligatorias \\ Conductas óptimas \\ Conductas deseables \\ Conductas prohibidas}

Son las conductas que, de acuerdo a la teoría ética o filosofía moral de la empresa, constituyen un deber ineludible y deben cumplirse siempre, sin excepción. El no cumplimiento de una conducta éticamente obligatoria provoca una falta por "omisión" de una conducta ineludible.

Son las que encarnan de forma excelente los ideales éticos de la empresa. Estos siempre deben ser buscados para perfeccionar al ser humano, a la organización y al conjunto de la sociedad.

Son las que no siempre pueden ponerse en práctica, pero en la medida que puedan concretarse, alientan 0 fortalecen los ideales de valores éticos asumidos por la empresa.

Son las que perjudican a la persona, a la organización o al conjunto de la sociedad en sus derechos fundamentales, de manera tal que jamás, en ninguna circunstancia, deben tolerarse. A través de la práctica prohibida se incurre en una falta por "acción". 
valores y la cultura organizacional y, finalmente, actuar en apego y respeto a las leyes, normas, valores y objetivos institucionales.

\section{ELABORACIÓN Y CONTENIDO DE LOS CÓDIGOS DE CONDUCTA}

La elaboración del código de conducta debe tomarse con mucha seriedad de parte de la organización, por la importancia que posee para la entidad y el personal. Se trata de un proceso que, si bien debe tener una cuota de participación, no resulta tan amplia como la necesaria para la redacción del Código de Ética, dado que este instrumento posee un carácter más detallado y técnico, lo cual demanda un conocimiento más especializado para su elaboración.

Se explica el proceso:

1. Constituir un Comité de Ética Institucional y asignar facultades y funciones para redactar dicho documento.

2. Analizar conductas riesgosas.

3. Identificar principios y determinar las conductas.

4. Redactar los borradores y presentar para su aprobación.

5. Determinar estrategias de comunicación y sensibilización.

6. Establecer actividades de verificación del cumplimiento e implementación de mecanismos de denuncia.

7. Realizar revisiones y actualizaciones periódicas al Código.

El rango superior de la empresa debe nombrar un comité de ética institucional que liderará el proceso. Está conformado por los integrantes de las otras unidades especializadas de la institución como: el Comité de Riesgos o el de Cum- plimiento, entre otros, y por miembros electos. Todo esto para representar todos los niveles jerárquicos de la organización de acuerdo con la estructura ocupacional.

Para que el comité entre en operación deberá redactar y aprobar, a lo interno de su estructura, la reglamentación que contenga los lineamientos de operación. Esto con la finalidad de puntualizar sus funciones, esquema de trabajo y coordinación para la elaboración del Código, así como lo referente a la organización y calendarización de las reuniones.

\section{- Analizar conductas riesgosas}

El Comité de Ética hará un listado de las situaciones de conflicto que haya tenido la empresa, así como la forma en que fueron atendidas y solucionadas. Para ello, se puede recurrir a varias herramientas tales como: diseñar y aplicar un cuestionario diagnóstico que considere preguntas para todos los colaboradores y terceros vinculados con la entidad, sobre los aspectos que causan conflicto internamente.

Dicho instrumento podrá aplicarse en forma grupal o vía internet y sus resultados serán tabulados para determinar las conductas de mayor incidencia. Como áreas de riesgo frecuentes se encuentran: manejo de la información, conflicto de intereses, uso de los recursos materiales y financieros, seguridad, salud y medio ambiente, relaciones entre los miembros del grupo y relación con el gobierno.

\section{- Identificar principios y determinar conduc- tas deseadas}

Una vez identificadas las conductas riesgosas, el Comité de Ética deberá definir los comportamientos esperados de los trabajadores, tomar una posición ética, objetiva e independiente ante las situaciones encontradas. Finalmente, debe identificar los principios conforme a los cuales la institución quiere que sus colaboradores rijan su actuación. 


\section{- Redactar los borradores y presentar para su aprobación}

El Comité de Ética determinará la estructura del Código de Conducta y seleccionará, a partir de la información recabada, las conductas contrarias a la integridad de mayor frecuencia, clasificándolas por rubros y a su vez dividiéndolas en conductas permitidas y no permitidas. Con lo anterior, podrá redactar el Código de Conducta, procurando utilizar un lenguaje sencillo, conciso y claro, estableciendo las consecuencias para quienes incurran en las conductas prohibidas. Deberá garantizarse que resulte compatible con el ordenamiento jurídico vigente del país y que respete los principios de proporcionalidad y razonabilidad, todo lo cual debe ser revisado y autorizado por el máximo nivel jerárquico de la organización.

\section{- Determinar estrategias de comunicación y sensibilización}

Una vez autorizado formalmente por los rangos superiores de la empresa, el Código de Conducta debe difundirse ampliamente, de manera interna y externa. Para ello, se debe recurrir a diversos medios que resulten idóneos para llevar a cabo la divulgación requerida como son: artículos, folletos, trípticos, boletines, carteles, correo electrónico y desde luego el intranet e internet.

De igual forma, se debe capacitar a todo el personal al momento de su ingreso, así como llevar un programa de capacitación periódica, respecto del Código de Conducta, y temas relacionados con la promoción de la integridad y prevención de la corrupción. A su vez, se debe proporcionar asesoría y comunicación sobre posibles irregularidades y demás temas vinculados.

\section{- Establecer actividades de verificación del cumplimiento e implementación de meca- nismos de denuncia}

El Código de Conducta debe prever mecanismos para garantizar su cumplimiento; de lo contrario, sería letra muerta. Para evitar esta situación, este debe incluir mecanismos de denuncia que incentiven la divulgación de los actos contrarios a los preceptos establecidos y a los valores corporativos, asegurando el anonimato y la estricta reserva de la información proporcionada por el denunciante, a fin de evitar el temor a represalias, como una línea de denuncia ética.

La atención de las denuncias, así como de las quejas o dudas que surjan de la aplicación de este instrumento, estarán a cargo del Comité de Ética responsable de la elaboración del citado código. Asimismo, la institución deberá contar con los protocolos de actuación para realizar el análisis de las denuncias y para llevar a cabo las acciones correspondientes por los incumplimientos detectados.

\section{- Realizar revisiones y actualizaciones perió- dicas a los códigos}

Un Código de Conducta no es un fin en sí mismo, es un instrumento dinámico, por lo cual se recomienda que se realice una revisión y actualización, por lo menos una vez al año. El Comité de ética es el responsable de dicha labor, para lo cual podrá recurrir a la aplicación de cuestionarios, consultas, grupos de discusión o los medios que la institución considere pertinentes para recabar las ideas y opiniones de la población trabajadora. En cuanto a la utilidad y conocimiento de este instrumento, y con base en esta realimentación, realizarán las modificaciones y actualizaciones que resulten procedentes, con la finalidad de hacer más eficiente esta herramienta. Dentro de su contenido general, se pueden encontrar los contenidos de la figura 3.

La divulgación del Código de Conducta debe ser permanente, al igual que la educación en ética y valores. Se trata de una actividad continua de la organización, con el fin de educar, recordar y reforzarle a quienes la integran los valores corporativos de la entidad. 
FIGURA 3

CONTENIDO DE LOS CÓDIGOS DE CONDUCTA
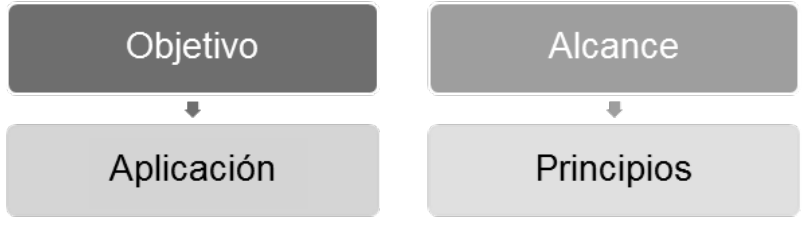

Principios
Acciones en caso de

incumplimiento

E.

Actualización del Código

Fuente: Elaboración propia, con base en la bibliografía consultada

\section{Diferencias con otras figuras afines}

Los códigos de ética y conducta suelen ser confundidos con otras figuras afines, que versan sobre las relaciones laborales, pero que responden a objetivos distintos. De allí la necesidad de clarificar su diferencia y mantener la identidad de estos instrumentos.

\section{DIFERENCIAS ENTRE EL CÓDIGO DE ÉTICA Y EL CÓDIGO DE CONDUCTA}

Aun cuando ambos instrumentos promueven los valores corporativos y procuran la consolidación de la ética organizacional, la transparencia y la buena imagen institucional no deben confundirse entre sí, dado que poseen diferencias. Estas se describen en la tabla 2.
En palabras sencillas, los códigos de ética son más generales, plasman los valores corporativos para cada área de relación relevante en la organización. Esto hace referencia a: relación con colegas de trabajo y superiores; relación con terceros; relación con el medio ambiente; entre otros. Además, carecen de sanciones. Por otro lado, los códigos de conducta son más específicos; desarrollan los valores corporativos seleccionados en el código de ética pero a través de conductas concretas y señalan las consecuencias de incurrir en actuaciones prohibidas o contrarias a dichos valores.

Ahora bien, frecuentemente las organizaciones incluyen los enunciados éticos al inicio del código de conducta y los denominan indistintamente códigos de ética o códigos de conducta. La primera parte de enunciados éticos correspon-

TABLA 2

\section{DIFERENCIAS ENTRE EL CÓDIGO DE ÉTICA Y EL CÓDIGO DE CONDUCTA}

\begin{tabular}{|l|l|}
\multicolumn{2}{|c|}{ Codigo de ética } \\
\begin{tabular}{|l|l|} 
Contiene los valores corporativos más relevantes de la organización en \\
diferentes áreas de vinculación.
\end{tabular} & $\begin{array}{l}\text { Desarrollan los valores corporativos plasmados en el código de ética por } \\
\text { medio de conductas específicas }\end{array}$ \\
\hline Enuncia valores sin describir situaciones concretas o conductas específicas. & Determinan una serie de reglas concretas de actuación. \\
\hline Enseñan y transmiten valores & Definen comportamientos, con base en criterios de ética e integridad \\
\hline Elaboración participativa con todos los niveles de la organización. & $\begin{array}{l}\text { Elaboración recae en un comité institucional y posteriormente es aproba- } \\
\text { do por el máximo nivel jerárquico de la organización. }\end{array}$ \\
\hline
\end{tabular}


de al código de ética y la segunda parte que incluye el detalle de las conductas sería el código de conducta, únicamente que se integran en un solo archivo, pero independientemente del nombre que se le otorgue, corresponde a dos instrumentos distintos.

\section{DIFERENCIAS CON LOS ACUERDOS MARCOGLOBALES}

Los acuerdos marco globales (AMG) son nuevos instrumentos en el derecho laboral que, sin poseer un carácter de leyes o normas propiamente dicho, vienen a coadyuvar en el respeto de los derechos y normativa laboral. Para la OIT, se definen como: un instrumento negociado entre una empresa multinacional y una federación sindical mundial con el fin de establecer una relación entre las partes y garantizar que la compañía respete las mismas normas en todos los países en los cuales opera.

Un acuerdo marco global (AMG) se da entre sindicatos de trabajadores, trabajadoras y representantes laborales que incluyen tanto a los empleados de dicha empresa a nivel mundial como a las cadenas de suministros. También, procura garantizar el respeto de los derechos y condiciones laborales mínimas requeridas en los convenios de la OIT.

El contenido de estos acuerdos depende de los requerimientos y las características de las empresas y los sindicatos que los suscriben, y de la forma en que se han desarrollado las relaciones laborales entre las partes. En todos los casos incluyen los cuatro principios y derechos fundamentales en el trabajo y hacen referencia específica a los convenios fundamentales de la OIT, pero varían otras cláusulas respecto a la demás normativa de la OIT, como la protección de los representantes de la población trabajadora, salarios, salud y seguridad ocupacional y formación profesional.
Para velar por su cumplimiento, se incluyen mecanismos de seguimiento en donde participan los sindicatos que negociaron el acuerdo, con acciones específicas por parte de la gerencia y los representantes designados por el personal, como la difusión en toda la empresa del acuerdo (y la traducción cuando sea necesaria) o el desarrollo de programas de capacitación conjuntos. Inclusive, llegan a incluir la realización de misiones conjuntas por el sindicato nacional interesado y la federación sindical mundial con el fin de realizar control de la aplicación del acuerdo en terreno y la posibilidad de que la federación sindical mundial pueda presentar un caso si considera que la compañía viola los términos del acuerdo.

Los códigos de ética y de conducta, aun cuando cuentan en su elaboración con la participación de sus integrantes, no son acuerdos, sino que entran dentro de los instrumentos unilaterales, disposiciones que los patronos imponen a sus subordinados. Inclusive los códigos de conducta prevén sanciones al incurrir en conductas prohibidas.

El objetivo del acuerdo marco global es garantizar el respeto de los derechos laborales mínimos, no solo entre los empleados de la empresa multinacional en todas las partes del mundo donde se lleven a cabo sus operaciones, incluyendo aquellos países con una legislación laboral más laxa que no se los garantiza, sino que también incluye al personal de la cadena de suministros. De tal manera, responden a objetivos distintos, los AMG buscan garantizar los derechos laborales mínimos mientras que, como se señaló anteriormente, los códigos de ética y conducta laborales buscan formar una cultura de ética organizacional basada en los valores corporativos. 


\section{DIFERENCIAS CON EL REGLAMENTO |INTERNO DE TRABAJO}

El reglamento interno de trabajo se define, en la legislación costarricense, como aquel elaborado por el patrono de acuerdo con las leyes, decretos, convenciones y contratos vigentes que lo afecten. Esto con el objeto de precisar las condiciones obligatorias a que deben sujetarse él y su personal con motivo de la ejecución o prestación concreta del trabajo.

La jurisprudencia de la Sala Segunda ha reconocido, al reglamento interno de trabajo, como una fuente de derecho que, si bien no puede ir en contra de la normativa general, sí crea obligaciones jurídicas tanto para la población trabajadora como para los representantes patronales. Al respecto la sentencia 1101-2012 dice:

El reglamento interno de trabajo constituye una fuente de derecho, con vocación generalizadora, por cuanto pretende regular las relaciones entre quien emplea y todas las personas que trabajan en su provecho. En el caso concreto, la reglamentación está vigente y debe ser aplicada hasta tanto no se derogue mediante la fórmula legal prevista para tales efectos. Aunque el contrato de trabajo también constituye una fuente de derecho, se tiene que aquella otra es general y más beneficiosa, sin que el legislador haya previsto la firma del contrato como un mecanismo para desplazar la validez y eficacia del reglamento interior. Además, aun cuando en el contrato se hace referencia a un nuevo Reglamento Interno de Trabajo, en los autos no consta que el invocado por la parte actora haya sido dejado sin efecto. Por consiguiente, se acoge la pretensión del accionante, haciendo la salvedad de que tiene derecho a que se le apliquen las consecuencias jurídicas de la norma, si al momento en que cumpla los presupuestos de hecho que se prevén, la misma se encuentra vigente.
El reglamento interno de trabajo debe ser aprobado de previo a su puesta en ejecución por la Oficina Legal, de Información y Relaciones internacionales del Ministerio de Trabajo y Seguridad Social. Debe ser puesto a conocimiento del personal, con quince días de anticipación a la fecha en que comenzará a regir. Se imprimirá en caracteres fácilmente legibles y se tendrá constantemente colocado, por lo menos, en dos de los sitios más visibles del lugar de trabajo. Asimismo, para eliminarlo o modificarlo debe seguirse con el mismo procedimiento establecido para su aprobación.

Respecto al contenido, se incluyen los aspectos de orden técnico y administrativo necesarios para la buena marcha de la empresa; las relativas a higiene y seguridad en las labores, como indicaciones para evitar que se materialicen los riesgos profesionales e instrucciones para prestar los primeros auxilios en caso de accidente $y$, en general, todas aquellas otras que se estimen convenientes. El numeral 68 del Código de Trabajo costarricense señala que estos instrumentos deben incluir los siguientes aspectos:

a. Las horas de entrada y de salida de los trabajadores, el tiempo destinado para las comidas y el período o períodos de descanso durante la jornada.

b. El lugar y el momento en que deben comenzar y terminar las jornadas de trabajo.

c. Los diversos tipos de salarios y las categorías de trabajo a que correspondan.

d. El lugar, día y hora de pago.

e. Las disposiciones disciplinarias y formas de aplicarlas. Es entendido que se prohíbe descontar suma alguna del salario de los trabajadores en concepto de multa y que la suspensión del trabajo, sin goce de sueldo, no podrá decretarse por más de ocho días 
ni antes de haber oído al interesado y a los compañeros que éste indique.

f. La designación de las personas del establecimiento ante quienes deberán presentarse las peticiones de mejoramiento o reclamos en general, y la manera de formular unas y otros.

g. Las normas especiales pertinentes a las diversas clases de labores, de acuerdo con la edad y sexo de los trabajadores.

Nótese que se trata de un instrumento que, jurídicamente y en su contenido, difiere de los códigos de ética y de conducta. El reglamento interno de trabajo posee un rango jurídico mayor que los citados códigos y establecen obligaciones que deben ser respetadas tanto por la población trabajadora como por la clase patronal. Para obtener validez jurídica, deben ser aprobados por el Ministerio de Trabajo, como una garantía de la legalidad de su contenido y que versan sobre diversos aspectos de la relación laboral. Podrá incluir elementos nuevos no regulados en el Código de Trabajo como el acoso sexual y el mobbing (acoso laboral), entre otros.

Por su parte, los códigos de ética y conducta poseen un rango jurídico menor, se aprueban a lo interno de la empresa o institución. También, se limitan a los aspectos vinculados con la ética organizacional y poseen un fin distinto, no tanto de regular la relación laboral, sino más bien, de incentivar los valores corporativos y consolidar una cultura organizacional ética.

\section{DIFERENCIAS CON EL CÓDIGO DE BUEN GOBIERNO CORPORATIVO}

El Gobierno Corporativo es un tema que ha tenido cada vez mayor importancia para las organizaciones. Se entiende como la correcta asignación de poderes y responsabilidades entre el directorio, la administración y la clase propietaria de una empresa. Esta definición reconoce que el Gobierno Corporativo no es solo un conjunto de reglas externas sino, más bien, una disciplina empresarial necesaria para mantener una relación estable y productiva entre los participantes de cualquier organización.

El Gobierno Corporativo propugna valores como la transparencia y la rendición de cuentas como ingredientes esenciales de una buena gestión y un requisito para la buena salud de las organizaciones. Para la Organización para la Cooperación y el Desarrollo Económicos (OCDE), el gobierno corporativo constituye un elemento clave para aumentar la eficacia económica y potenciar el crecimiento, así como para fomentar la confianza de los inversores. El gobierno corporativo abarca toda una serie de relaciones entre el cuerpo directivo de una empresa, su Consejo, sus accionistas y otras partes interesadas.

Las empresas públicas y privadas recurren a los Códigos de Buen Gobierno Corporativo para tipificar las reglas que regirán las relaciones entre las partes que integran el gobierno corporativo, entre las cuales se puede incluir al personal. No obstante, este código responde a necesidades distintas de las atendidas en los códigos de ética y de conducta.

En ellos, la ética en los negocios y la conciencia de las empresas sobre los intereses medioambientales y sociales de las comunidades en las que desarrollan su actividad se toman en cuenta por la repercusión que tienen sobre la imagen de la empresa; sin embargo, no se trata del tipo de reglas que integra al respecto el código de ética o código de conducta. Asimismo, aun cuando se pueden compartir aspectos esenciales como los valores corporativos, ambos institutos responden a intereses y fines distintos y poseen utilidades diversas para la empresa, por lo que más bien se trata de documentos complementarios. 


\section{Importancia de los códigos de ética y conducta en la promoción de la ética organizacional}

Los códigos de ética y conducta detallan los valores organizacionales, los principios morales y profesionales que deben guiar su actuación. Además, establecen la conducta esperada por ellos en determinadas situaciones, con lo cual les otorgan claridad y seguridad jurídica a ambas partes en la relación laboral.

El objetivo de estos instrumentos es promover los valores corporativos, consolidar la ética organizacional y contribuir a mejorar el clima organizacional. Dichos aspectos, en su conjunto, permiten construir una cultura organizacional basada en los valores que caracteriza a la empresa o institución.

Dichos códigos deben ser conocidos por todos los trabajadores, por lo que su divulgación debe ser amplia e incluso se recomienda que sean firmados por ellos, lo que contribuye a promover su lectura y a documentar la conformidad del personal con ellos. Igualmente deben ser dados a conocer a los terceros que poseen vinculación económica, institucional o comercial con la empresa (proveedores, usuarios/clientes, entidades gubernamentales, ciudadanía en general), para que tomen conciencia de los valores que rigen la entidad y la actuación que se demanda de ellos cuando se relacionen con la empresa; por ejemplo, la prohibición de entrega de regalos u otro tipo de prácticas que puedan ser consideradas como soborno a los empleados de la entidad. Inclusive, la divulgación de dichos instrumentos en la ciudadanía en general permite incrementar la fiscalización de la conducta ética de los trabajadores y terceros vinculados con ella y la presentación de denuncias en contra de aquellos que incumplen dichos deberes, pues tendrán un mayor conocimiento de aquellas prácticas prohibidas y que no representan a la organización.
Los códigos de ética y códigos de conducta son instrumentos valiosos para la promoción de la ética organizacional. Aunque por sí mismos no garantizan un actuar ético de parte de los funcionarios, trabajadores y terceros vinculados con la empresa, sí corresponden a un documento que promueve los valores corporativos, brindan una imagen de compromiso ético, tanto interna como externa y otorgan seguridad jurídica al establecer claramente cuál es la conducta esperada, la conducta prohibida y las sanciones por vulnerar los mandatos éticos de la organización. Su principal aporte radica en codificar el compromiso ético organizacional y reforzar sus valores de cara a los trabajadores, terceros, clientes y sociedad en general.

Finalmente, se debe destacar que cada empresa u organización es un sistema único, con características, requerimientos, objetivos y entorno específicos. Por ende, debe construir su propio sistema de valores e identidad organizacional; labor en la cual los códigos de ética y conducta contribuyen de forma relevante.

\section{CONCLUSIONES}

Los códigos de ética y códigos de conducta son instrumentos fundamentales para la determinación de los valores corporativos que deben guiar la actuación de los colaboradores de una empresa en los diferentes ámbitos de relación. Con esto se habla de compañeros y superiores, proveedores, clientes/usuarios, las autoridades gubernamentales, terceros y la sociedad en general.

El Código de ética define, en forma colaborativa con la participación de toda la clase trabajadora y dirigente, los valores corporativos que serán desarrollados mediante conductas específicas en el código de conducta donde se detallan las actuaciones esperables, aquellas que están prohibidas y las consecuencias de incurrir en ellas. 
Dichos instrumentos, si bien poseen un rango jurídico menor, pues no pueden ir en contra o incluir aspectos más allá de los establecidos por ley, corresponden a una buena práctica en materia laboral, que otorga seguridad y reglas claras a los trabajadores y terceros vinculados con la empresa. Procuran consolidar la ética organizacional basada en valores y mejorar el clima organizacional que permita construir una cultura organizacional basada en conductas éticamente correctas para la empresa u organización, de allí su importancia en el ámbito laboral.

Lo expuesto los convierte en importantes instrumentos de promoción de la ética organizacional que mejora la imagen de la entidad, tanto interna como externa. A su vez, se logra minimizar los efectos negativos de verse involucrados, ante la opinión pública, en prácticas antiéticas y son una herramienta útil para atender la preocupación ética que hoy demanda actuaciones concretas de parte de las empresas tanto públicas como privadas.

\section{REFERENCIAS}

Asamblea Legislativa. (1943). Código de Trabajo. Sistema Nacional de Legislación Vigente, Costa Rica.

Auditoría Superior de la Federación. (2013). Código de Conducta. Cámara de los Diputados. México.

Auditoría Superior de la Federación. (2013). Código de Ética. Cámara de los Diputados. México

Belalcázar, B. S. (2012). Cultura organizacional. Informes Psicológicos, 12(1), 41-51.
Cleghorn. E. L. (2005). Gestión ética para una organización competitiva. Bogotá, Colombia.

Domínguez, L. R., Ramírez, A. F., \& García Méndez A. (2013). El clima laboral como un elemento del compromiso organizacional. Revista Nacional de Administración, 4(1), 59-70.

Elegido, J. M. (1998). Fundamentos de ética de empresa: La perspectiva de un país en desarrollo. Instituto Panamericano de Alta Dirección de Empresa (IPADE), México.

Hutman, K. (2005). Evaluating Organizational Values. Organizational Development Journal, 23(3), 39-48.

González, A. C. (2004). Código de ética para una empresa agroindustrial. (Tesis de maestría). Universidad de Costa Rica, San José, Costa Rica.

Gilli, J. J. (2011). Ética y empresa: valores y responsabilidad social en la gestión. Buenos Aires: Granica.

Organización para la Cooperación y el Desarrollo Económicos, (OCDE). (2004). Principios de Gobierno Corporativo. París, Francia.

Sala Segunda de la Corte Suprema de Justicia de Costa Rica. (2012). Sentencia 1101-2012. San José: Sistema Nacional de Legislación Vigente (SINALEVI).

Velásquez, Y., Rodríguez, C., \& Guaita, W. (2012). Los valores organizacionales: Referencia para la evaluación de la producción. 6th International Conference on Industrial Engineering and Industrial Management. XVI Congreso de Ingeniería de Organización. Vigo, July 18-20.

Recibido: 26 de setiembre de 2017

Aceptado: 10 de diciembre de 2017 